\title{
A SEGURANÇA JURÍDICA DA POSSE COMO PRESSUPOSTO DO DIREITO FUNDAMENTAL À MORADIA ${ }^{1}$
}

\section{LEGAL SECURITY OF TENURE AS A PREMISE OF THE FUNDAMENTAL RIGHT TO HOUSING}

Josué Mastrodi²

Ederson dos Santos Alves ${ }^{3}$

\begin{abstract}
Resumo
Este estudo tem por objetivo analisar um dos pressupostos garantidores da efetivação do direito à moradia, a segurança jurídica da posse, nos termos da Recomendação Geral n. 4 do Comitê das Nações Unidas para os Direitos Sociais, Econômicos e Culturais. Considerando a moradia como um direito fundamental autônomo, previsto no artigo 60 da Constituição Federal de 1988, discutimos a possibilidade de aplicar, a qualquer moradia, a segurança jurídica da posse já prevista no Código Civil brasileiro, qual seja, o instituto do direito real de habitação, que protege o cônjuge supérstite e the assegura a moradia mesmo após a morte do cônjuge proprietário do imóvel, em detrimento dos interesses de sucessores hereditários. Nessa situação, embora muito específica, verifica-se o pressuposto da segurança jurídica da posse, que é objeto de recomendação pela ONU, e que se pretende ver ampliado às demais situações de segurança da posse. Para o desenvolvimento desta pesquisa, comparamos a legislação e a posição jurisprudencial dos tribunais superiores brasileiros sobre direito real de habitação aos documentos internacionais que tratam da proteção do direito à moradia adequada, como a já mencionada Recomendação Geral n. 4 e a Agenda Habitat, assim como a meta 11 dos objetivos do Milênio.
\end{abstract}

Palavras-chave: Direito à Moradia; Moradia Adequada; Moradia como Direito Fundamental Autônomo; Direito Real de Habitação; Segurança Jurídica da Posse.

\section{Abstract}

This paper aims to analyse one of the grant premises that guarantees the right to adequate housing, which is the "legal security of tenure", in accordance with the provisions of United Nations Committee on Economic, Social and Cultural Rights in its General Comment n. 4. Taking into account housing as an autonomous fundamental right, set forth in article $6^{\text {th }}$ of 1988 Brazilian Constitution, we discuss whether is possible to apply to any housing the concept of legal security of tenure that already exists in the Brazilian Civil Law system, that is the Direito Real de Habitação institute, which basically guarantees the spouse to remain in the home when partner fades away, despite the interest of legal inheritors. In this situation, although its exceptionality, is possible to identify the premise of legal security of tenure, which is the object of recommendation by the

\footnotetext{
${ }^{1}$ Os autores agradecem às importantes considerações apresentadas pelos (as) Avaliadores (as) da Revista de Direito da Cidade, que muito contribuíram para o aprofundamento do tema. Eventuais equívocos, não obstante, permanecem de responsabilidade dos autores.

2 Doutor em Filosofia e Teoria Geral do Direito pela USP. Professor da Faculdade de Direito da PUC-Campinas. Professor do Programa de Pós-Graduação stricto sensu em Sustentabilidade da PUC-Campins. E-mail: mastrodi@puc-campinas.edu.br

${ }^{3}$ Aluno de graduação da Faculdade de Direito. Membro do Grupo de Estudos Direito e Realidade Social. Email: ederson.sa@live.com
} 
United Nations Organization, which we intend to broaden it to any other situations involving legal security of tenure. For the development of this research, we have compared Brazilian law and the precedents of main Brazilian tribunals on the Direito Real de Habitação institute to international documents that deal with the protection of the right to adequate housing, such as the aforementioned General Comment 4 and the Habitat Agenda, as well as the goal 11 of the Millennium Declaration.

Keywords: Right to Housing; Adequate housing; Housing as an autonomous fundamental right; The Institute of Direito Real de Habitação; Legal security of tenure. 


\section{INTRODUÇÃO}

Esta pesquisa se propõe a analisar a segurança jurídica da posse como um dos principais fundamentos para a concretização do direito à moradia adequada.

A expressão segurança jurídica da posse decorre, por óbvio, do conceito de segurança jurídica, considerado ora valor, ora princípio, ora norma fundamental da estrutura orgânica de qualquer sistema normativo. Ela se refere à necessidade de previsão ou previsibilidade da realização das consequências (ou expectativas) previstas normativamente em qualquer sociedade civil.

Tal segurança é maior ou menor conforme os interesses sociais envolvidos. Certos direitos, por serem entendidos como mais importantes, possuem mais garantia normativa e, portanto, mais segurança ou previsibilidade. Desde o estabelecimento do Estado de Direito, ${ }^{4}$ o direito à propriedade tem sido um dos direitos mais protegidos e, portanto, um dos mais seguros ou com mais segurança jurídica. Já a posse, por ser comumente entendida em seu caráter acessório em relação à propriedade, não tem um histórico de segurança jurídica, ao menos não com a mesma relevância dada à propriedade.

No presente artigo, pretende-se discutir a segurança da posse com base em duas situações. A primeira, que há muito tempo já existe no direito brasileiro, que provê segurança da posse na hipótese de direito real de habitação de cônjuge supérstite contra os herdeiros do imóvel em que se dá a moradia.

A segurança da posse, reconhecida no direito internacional, acaba sendo tutelada, no Brasil, tão somente em favor do cônjuge supérstite contra os novos proprietários, herdeiros do cônjuge falecido. Nesta situação, muito específica e excepcional no âmbito do direito privado, o cônjuge sobrevivente tem o direito de continuar a habitar gratuitamente o imóvel alheio, mesmo não sendo o dono, não possuindo título legal, uma vez que o direito real de habitação garante a ele, mesmo não recebendo legado ou não tendo direito a partilha, o direito de permanecer no imóvel que lhe serve de moradia. Este instituto não afeta a propriedade abstrata, por tratar-se de direito de fruição reduzido, que consiste no poder de ocupação gratuita de casa alheia. O direito

\footnotetext{
${ }^{4}$ A respeito da compreensão do conceito de segurança jurídica e sua evolução desde a estruturação histórica do Estado de Direito, passando pelo Estado de bem-estar social e pelo Estado democrático de Direito, cf. Costa (2014).
} 
real de habitação está disciplinado nos artigos 1.410, 1.414, 1.415, 1.416 e 1.831 do Código Civil brasileiro. $^{5}$

Em que pese tal proteção à moradia ocorrer apenas nesta situação específica, e que por regras hermenêuticas não se admite interpretação extensiva de uma exceção a outras situações análogas, o direito real de habitação não é prescrito apenas no âmbito do direito privado. $\mathrm{O}$ artigo 6o da Constituição Federal de 1988 prevê o direito à moradia como direito fundamental autônomo, que autoriza compreender o direito real de habitação não como exceção às regras de direito privado, mas como uma situação de promoção da moradia em detrimento da propriedade. Nesse sentido, o que impede que se estenda a proteção do direito real de habitação para os demais casos de proteção ao direito à moradia, promovendo a segurança jurídica da posse de imóveis ocupados e sem justo título de propriedade em favor de seus ocupantes? O que impede que a segurança da posse seja considerada universal, com fundamento constitucional, em qualquer disputa envolvendo moradia, e não apenas nas questões entre cônjuge supérstite e herdeiros, futuros proprietários do imóvel?

Referimo-nos, assim, a uma segunda situação de estudo, qual seja, a assentamentos informais de baixa renda, em que moradores ocupam terrenos de propriedade alheia, de forma mansa e pacífica, sem tempo para se cumprir o tempo necessário para se consumar a prescrição aquisitiva (usucapião). Aliás, mesmo quando já houve prescrição aquisitiva, incontáveis decisões judiciais em ações possessórias têm determinado, quase que invariavelmente, que tal posse é insegura, precária, determinando a expulsão dos moradores (por exemplos, os famosos casos

\footnotetext{
${ }^{5}$ Art. 1.410. O usufruto extingue-se, cancelando-se o registro no Cartório de Registro de Imóveis:

I - pela renúncia ou morte do usufrutuário; [...]

VIII - Pelo não uso, ou não fruição, da coisa em que o usufruto recai (arts. 1.390 e 1.399).

Art. 1.414. Quando o uso consistir no direito de habitar gratuitamente casa alheia, o titular deste direito não a pode alugar, nem emprestar, mas simplesmente ocupá-la com sua família.

Art. 1415: Se o direito real de habitação for conferido a mais de uma pessoa, qualquer delas que sozinha habite a casa não terá de pagar aluguel à outra, ou às outras, mas não as pode inibir de exercerem, querendo, o direito, que também lhes compete, de habitá-la.

Art. 1.416. São aplicáveis à habitação, no que não for contrário à sua natureza, as disposições relativas ao usufruto.

Art. 1.831. Ao cônjuge sobrevivente, qualquer que seja o regime de bens, será assegurado, sem prejuízo da participação que the caiba na herança, o direito real de habitação relativamente ao imóvel destinado à residência da família, desde que seja o único daquela natureza a inventariar.
} 
havidos no Estado de São Paulo, de Pinheirinho, ${ }^{6}$ em São José dos Campos, e de Vila Soma, ${ }^{7}$ em Sumaré).

Indo além, havendo necessidade ou urgência em caso de remoção, segundo a discricionariedade do Administrador Público, costuma-se aplicar, aos proprietários dos imóveis expropriados, a lei de desapropriação, com pagamento de indenização prévia, justa e em dinheiro ao desapropriado (art. 5으, inciso XXIV, da Constituição Federal). ${ }^{8}$ Porém, não se costuma indenizar o morador pela perda da moradia, pois este não possui justo título e não há previsão, na lei de desapropriação, de indenização aos moradores, que não possuem segurança da posse contra a Administração Pública em casos de desapropriação. ${ }^{9}$

No Brasil, não se indeniza a posse, apenas a propriedade e as eventuais benfeitorias. O direito de morar ainda não é ressarcível em caso de perda, lesão ou ameaça, ou seja, a indenização ao direito de morar não é apreciada pelo Poder Público. Assim, embora o Estado reconheça como válida a norma que define a moradia como direito fundamental, esse mesmo Estado não reconhece o direito à moradia adequada no caso de famílias desalojadas, que ficam sem moradia e sem qualquer ressarcimento por tal perda, ainda que essa perda possa ser perfeitamente representada em termos monetários de modo a ser definido algum valor a título indenizatório. fato de morar tem sido considerado irrelevante para fins de indenização, deixando-se claro que a moradia não é encarada como direito fundamental, fazendo-se letra morta da disposição constitucional que inclui a moradia entre os direitos fundamentais.

6 Cf. ação de reintegração de posse na comunidade Pinheirinho. Disponível em: <https://esaj.tjsp.jus.br/cjsg/getArquivo.do?cdAcordao=8783484\&cdForo=0>. Acesso em 08 set. 2016.

${ }^{7} \mathrm{Cf}$. ação de reintegração de posse da Vila Soma, a reportagem mostra uma das maiores ações da história do judiciário no Estado de São Paulo. Disponível em:<http://correio.rac.com.br/_conteudo/2015/05/capa/campinas_e_rmc/257392-vila-soma-as-duas-facesde-um-drama.html>. Acesso em: 13.set. 2016.

${ }^{8}$ O Art. 5o, inciso XXIV -"a lei estabelecerá o procedimento para desapropriação por necessidade ou utilidade pública, ou por interesse social, mediante justa e prévia indenização em dinheiro, ressalvados os casos previstos nesta Constituição";

${ }^{9}$ Um aspecto interessante da proteção jurídica da posse, no âmbito do Direito Público, está no estudo sobre os institutos da concessão de direito real de uso e da concessão de uso especial para fins de moradia, instrumentos de política urbana previstos no artigo 4ㅇ, III, alíneas ' $g$ ' e ' $h$ ', do Estatuto da Cidade, relacionados à possibilidade de bens públicos dominicais, que não são passíveis de usucapião, serem destinados a moradia de seus ocupantes. Esses institutos também estão previstos, respectivamente, no art. 48 do Estatuto da Cidade e na Medida Provisória 2220/2001. Tal discussão foi desenvolvida em Mastrodi e Martins (2016) e foge do objeto deste estudo, que está voltado a uma abordagem específica dentro do Direito Privado. 
A Declaração Universal dos Direitos Humanos de 1948 reconheceu o direito à moradia como elemento essencial para uma vida adequada, devendo ser assegurado como um direito humano, afirmação que se deu novamente ao menos em outras três oportunidades: em 1966, com o Pacto dos Direitos Sociais, Econômicos e Culturais; em 1991, com a Recomendação Geral n. 4 do Comitê das Nações Unidas para os Direitos Sociais, Econômicos e Culturais, e com o advento da Declaração de Istambul sobre Assentamentos Humanos no ano de 1996, também conhecida como Agenda Habitat II, que tratou do direito à moradia como mínimo essencial para que se possa ter uma vida digna.

A propósito, o Pacto Internacional de Direitos Econômicos, Sociais e Culturais de 1966 (PIDESC), que foi ratificado pelo Brasil em 1992, dispõe em seu artigo 11.1:

Os Estados-partes do presente Pacto reconhecem o direito a de toda pessoa a nível de vida adequando para si e sua família, inclusive à alimentação, vestimenta e moradia adequada, assim como uma melhoria continua de suas condições de vida.

O PIDESC determina com que os Estados-partes assumam o dever de reconhecer, respeitar e proteger, assim como assegurar a promoção da moradia, uma vez que os elementos da moradia adequada dependem mutuamente uns dos outros para sua efetivação, não havendo como ser auferidos isoladamente. Isto é, moradia adequada pressupõe, além do teto e das quatro paredes, integração da moradia ao bairro e à cidade, com presença de equipamentos e serviços públicos de saúde, educação, transporte, lazer etc. (MASTRODI e ISAAC, 2016, p. 736). A produção de moradias que não possuam essas características é contraditória quando pensamos na cidade como um local onde as pessoas vivem de forma coletiva, onde elas possuem (ou deveriam possuir) condições para realização de direitos básicos, como acesso a saúde, a educação e a transporte público para seu local de trabalho ou de lazer.

Por força da ratificação do PIDESC em 1992 pelo Brasil, a moradia passou a ser direito fundamental, nos termos do parágrafo 2 do art. 5 da Constituição Federal, que determinava que os tratados de direitos humanos dos quais o Brasil fosse parte teriam força de norma constitucional. Não obstante, no ano 2000, o direito à moradia se tornou expressamente direito fundamental, por sua positivação no artigo 60 da Constituição, ${ }^{10}$ por força da Emenda Constitucional 26. Na verdade, a Constituição já estatuía, por força do Poder Constituinte

\footnotetext{
10 "Art. 6o São direitos sociais a educação, a saúde, a alimentação, o trabalho, a moradia, o lazer, a segurança, a previdência social, a proteção à maternidade e à infância, a assistência aos desamparados, na forma desta Constituição".
} 
Originário, isto é, desde 1988, que moradia faz parte das necessidades básicas de qualquer trabalhador ou de sua família, nos termos de seu art. 70, IV. ${ }^{11}$ De igual modo, já afirmava em seu art. 23, IX, que o Estado, em suas três esferas, deve promover a melhoria das condições habitacionais e de saneamento básico, bem como estimular programas de construção de moradias. $^{12}$

A Recomendação ${ }^{13}$ Geral n. 4 das Nações Unidas (1991) descreve quais são os pressupostos para uma moradia adequada: a segurança jurídica da posse figura como o primeiro de uma lista, seguida de disponibilidade de serviços e infraestrutura urbana, custo acessível, habitabilidade, acessibilidade, localização e adequação cultural.

Estas são as características que se devem observar para que uma moradia possa ser considerada uma moradia adequada, pois estes pressupostos visam garantir a efetivação do direito à moradia digna e adequada, não tão somente uma moradia.

Portanto, a moradia adequada compõe-se de um conjunto de serviços que deve atender às necessidades de seus moradores. Assim, para ser considerada adequada, não basta haver simplesmente uma casa, a moradia deve reunir os vários requisitos supramencionados.

Segundo as diretrizes das Nações Unidas e, em especial, por força do Pacto de 1966, a moradia foi compreendida como uma condição básica para alcançar os outros direitos individuais e sociais. O PIDESC reafirma a participação e colaboração do setor Público, bem como dos entes privados, na busca pela concretização do direito à moradia adequada, principalmente para aqueles em condições de pobreza extrema e grupos vulneráveis.

Ademais, cabe ressaltar, aqui, que ter os mesmos direitos sem as mesmas condições de reivindicação não equivale a ter os mesmos direitos.

Não se espera, certamente, o esgotamento do tema, pois o foco deste artigo se restringe a apenas alguns aspectos da segurança da posse, em especial sua concretização de forma universalizada. As demais condições que dão conteúdo mínimo de direito humano ao direito à

\footnotetext{
11 Artigo 70, IV - salário mínimo, fixado em lei, nacionalmente unificado, capaz de atender a suas necessidades vitais básicas e às de sua família com moradia, alimentação, educação, saúde, lazer, vestuário, higiene, transporte e previdência social, com reajustes periódicos que lhe preservem o poder aquisitivo, sendo vedada sua vinculação para qualquer fim;

${ }^{12}$ Artigo 23, "IX - promover programas de construção de moradias e a melhoria das condições habitacionais e de saneamento básico;"

13 Entendemos o termo "Recomendação" mais adequado que a tradução costumeiramente dada ao termo "Comment" ("Comentário"). Cf. MASTRODI e MARTINS (2016).
} 
moradia, embora sejam indiretamente tratadas ora ou outra ao longo deste trabalho, fogem do escopo da presente pesquisa, embora sejam temas de grande relevo.

Outra observação importante deve ficar desde logo explícita: nos termos aqui propostos, conforme fundamento no inciso XXIII do artigo 5o da Constituição Federal de 1988, não se afirmar qualquer direito à moradia sobre imóvel alheio pelo fato de o imóvel ser alheio, mas pelo fato de o imóvel não cumprir a função social da propriedade e, por ocioso, poder ser ocupado de forma mansa e pacífica.

A hipótese deste trabalho consiste em verificar a possibilidade de se estender a segurança jurídica da posse, prevista no direito real de habitação, a todos os casos de proteção ao direito à moradia. Se confirmada esta hipótese, o morador poderia usar medidas de proteção possessória para assegurar o seu direito real sobre imóvel alheio, podendo, inclusive, demandar contra o titular da propriedade ou qualquer outro que ameaçar seu direito de moradia.

Este trabalho está estruturado em três tópicos: no item 1, tratamos sobre a segurança jurídica da posse e sua relevância nos âmbitos nacional e internacional. No item 2, abordamos os conceitos de posse como moradia e versamos a respeito da proteção ao direito à moradia segundo a Agenda Habitat e a meta 11 da Declaração do Milênio das Nações Unidas. No item 3, por sua vez, tratamos do instituto do direito real de habitação e alguma consolidação jurisprudencial. Algumas considerações são desenvolvidas ao final, à guisa de conclusão.

\section{A SEGURANÇA JURÍDICA DA POSSE COMO UM PRESSUPOSTO GARANTIDOR DA EFETIVAÇÃO DO DIREITO À MORADIA}

Conforme a Recomendação Geral n.4 do Comitê das Nações Unidas para Direitos Sociais, Econômicos e Culturais, a moradia adequada é definível pelas seguintes características:

Segurança da posse: a moradia não é adequada se os seus ocupantes não têm um grau de segurança de posse que garanta a proteção legal contra despejos forçados, perseguição e outras ameaças.

Disponibilidade de serviços, materiais, instalações e infraestrutura: a moradia não é adequada, se os seus ocupantes não têm água potável, saneamento básico, energia para cozinhar, aquecimento, iluminação, armazenamento de alimentos ou coleta de lixo.

Economicidade: a moradia não é adequada, se o seu custo ameaça ou compromete o exercício de outros direitos humanos dos ocupantes.

Habitabilidade: a moradia não é adequada se não garantir a segurança física e estrutural proporcionando um espaço adequado, bem como proteção contra o frio, umidade, calor, chuva, vento, outras ameaças à saúde. 
Acessibilidade: a moradia não é adequada se as necessidades específicas dos grupos desfavorecidos e marginalizados não são levados em conta.

Localização: a moradia não é adequada se for isolada de oportunidades de emprego, serviços de saúde, escolas, creches e outras instalações sociais ou, se localizados em áreas poluídas ou perigosas.

Adequação cultural: a moradia não é adequada se não respeitar e levar em conta a expressão da identidade cultural (NAÇÕES UNIDAS, 1991).

Os moradores, independentemente de serem proprietários de suas habitações, devem contar com meios que garantam um grau de segurança jurídica da posse contra desalojamentos forçados e outras ameaças, ou seja, uma proteção legal contra qualquer ato ou fato que lhes turbe a permanência no local. Uma proteção a ser garantida pelo Estado e que proporcione segurança aos moradores.

Segurança legal de posse. A posse toma uma variedade de formas, incluindo locação (pública e privada), acomodação, habitação cooperativa, arrendamento, uso pelo próprio proprietário, habitação de emergência e assentamentos informais, incluindo ocupação de terreno ou propriedade. Independentemente do tipo de posse, todas as pessoas deveriam possuir um grau de sua segurança, o qual garanta proteção legal contra despejos forçados, pressões incômodas e outras ameaças. Estados-partes deveriam, consequentemente, tomar medidas imediatas com o objetivo de conferir segurança jurídica de posse sobre pessoas e domicílios em que falta proteção, em consulta real com pessoas e grupos afetados (NAÇÕES UNIDAS, 1991).

A segurança jurídica da posse garante que uma pessoa ou um grupo deve ter a garantia de alguma proteção legal, ou seja, que seja assegurada a continuidade temporal contra desalojamento forçado, independentemente do tipo de posse, evitando qualquer ameaça ou lesão ao direito de moradia, uma vez que essa falta de proteção compromete ou deteriora a qualidade de vida dessas pessoas. Assim, caberia aos Estados-Parte do PIDESC trabalharem visando à construção dessa segurança. Neste mesmo posicionamento discorrem Alfonsin e Fernandes:

Para garantir a segurança da posse como forma de assegurar o direito à moradia é necessário que os países legalmente reconheçam a diversidade das formas de uso e ocupação do solo presentes nas áreas urbanas e rurais, por meio das normas nacionais de direito à moradia (ALFONSIN e FERNANDES, 2004, p. 35).

Além disso, os autores asseveram que os Estados-Partes devem procurar reconhecer as diversas formas de uso nas áreas urbanas, sugerindo que tal fato seja realizado por meio das normas nacionais de proteção ao direito à moradia.

Segundo disposto no informativo "Por uma Cultura de Direitos Humanos: Direito à moradia adequada", da Secretaria de Direitos Humanos da Presidência da República Federativa do Brasil, em relação ao direito à moradia adequada, o Estado detém três tipos de obrigações: "a obrigação 
de se abster de atos que ofendam tal direito, de proteger a moradia contra a intervenção de terceiros e de atuar para sua realização. A moradia integra o direito a um mínimo existencial" (SECRETARIA DE DIREITOS HUMANOS, 2013, p. 39).

Observa-se, também, que não há eficácia social do direito fundamental à moradia, principalmente quando entendido como direito à moradia adequada, se o Estado puder alegar a insuficiência de recursos para não realizar tais investimentos ou obras. Essa teoria, conhecida como "reserva do possível", tem sido frequentemente associada à escusa do Estado para não concretização de direitos sociais.

Ao contrário de outros direitos fundamentais que se podem pleitear na esfera judicial, à guisa de exemplo, a questão de um remédio ou uma cirurgia ou até mesmo vaga em creche, havendo ordem judicial, a Administração é obrigada a cumprir, já que esses produtos ou serviços encontram-se, em tese, "em estoque", ou seja, já são prestados pelo Estado, bastando apenas a inclusão daquele que o pleiteou na via judicial (MASTRODI e ROSMANINHO, 2013, p. 113-134).

Segundo consagra a Lei no 10.257, de 2001, Estatuto da Cidade, que regulamenta os artigos 182 e 183 da Constituição Federal, a concessão de uso especial de bem público para atender ao fim de moradia é considerado um dos instrumentos de proteção jurídica da posse, haja vista que, como bens públicos não são passíveis de usucapião, a concessão de uso garante ao posseiro a segurança da posse sobre o bem que passou a usar a título de moradia. ${ }^{14}$

A respeito da violação da segurança da posse, Saule Jr (2005, p. 33) é assertivo ao considerar que a segurança de posse é uma proteção jurídica que confere dignidade ao morador, em virtude de eliminar o temor das ameaças de despejo, conferindo planejamento familiar e investimentos na melhoria de sua habitação.

Sem segurança jurídica, os moradores possuidores não têm proteção legal para viver com dignidade e paz, já que sua posse é compreendida como um fato sempre precário e, muitas vezes, contrário ao direito de propriedade. Estes moradores tendem a viver com o temor de ameaças de despejo, o que compromete sua qualidade de vida, já que a insegurança dificulta circunstâncias normais e importantes da vida cotidiana. Essa segurança, negada aos moradores de ocupações irregulares, deveria decorrer da proteção ao direito à moradia, a ser tratado no próximo item.

\footnotetext{
${ }^{14}$ Esta questão é mais bem desenvolvida em Mastrodi e Martins (2016).
} 


\section{DA PROTEÇÃO AO DIREITO À MORADIA}

A proteção ao direito à moradia costuma encontrar um obstáculo intransponível: a moradia é confundida com o elemento posse da propriedade, o que impede de compreender o direito à moradia como um direito fundamental autônomo em relação ao direito à propriedade. ${ }^{15}$ Nesse sentido, quem possui direito à moradia não teria segurança na posse quando tal direito colidisse com o direito do proprietário do imóvel, já que a posse pertenceria, segundo a teoria geral do Direito, a este e não àquele. ${ }^{16}$

Cabe fazer ressalva quanto à distinção entre posse e propriedade segundo a teoria mais tradicional do Direito. Segundo Costa (1998, p. 109), em referência ao Código Civil, "a propriedade é o mais amplo direito sobre a coisa, envolvendo os poderes de usar, fruir e dispor da mesma (alienar, gravar, consumir, alterar e até destruir) e de reivindicá-la do poder de quem injustamente a possua (art. 524)". Quanto à posse, este mesmo autor afirma que "[...] é mero instrumento, meio ou forma de se exercer o direito de propriedade e o direito real limitado, usando diretamente a coisa ou por meio de terceiro (fruindo), ou resgatando o seu valor pela transferência do direito real e da posse a terceiro [...]" (COSTA, 1999, p. 110). Nesse mesmo sentido e de modo bem sintético, Ihering $(1908$, p.8) já afirmava que "a posse é o poder de fato e a propriedade, o poder de direito sobre a coisa".

\footnotetext{
${ }^{15}$ Rousseau possui uma frase célebre sobre a relação entre propriedade privada de sociedade civil. Em seu discurso sobre as causas da desigualdade entre os homens, apontou a propriedade privada como o fundamento de toda essa desigualdade: "O primeiro que, tendo cercado um terreno, atreveu-se a dizer: Isto é meu, e encontrou pessoas simples o suficiente para acreditar nele, foi o verdadeiro fundador da sociedade civil. Quantos crimes, guerras, assassínios, quantas misérias e horrores não teria poupado o gênero humano aquele que, arrancando as estacas ou enchendo o fosso, houvesse gritado aos seus semelhantes: evitai ouvir esse impostor..." (1999, p. 203). Toda propriedade privada distingue mas, ao mesmo tempo, exclui. O Direito Civil está estruturado quase que completamente sobre a proteção da propriedade privada, o que acaba sendo um grande obstáculo a quaisquer discussões democráticas sobre, por exemplo, uso e ocupação de áreas urbanas. No presente estudo, a questão não envolve tanto o uso de áreas urbanas, como é a prática do Grupo de Pesquisa Direito e Realidade Social, ao qual pertencem os autores, mas sim à questão da proteção jurídica da posse, que acaba por não receber proteção adequada, muitas vezes, por estar em oposição ao direito de propriedade, sobre o qual o Direito Civil se funda.

${ }^{16}$ Vale referência aos textos de MASTRODI e ROSSI (2015) e MASTRODI e ROSMANINHO (2013), em que os autores tratam especificamente da autonomia do direito fundamental à moradia, desvinculando-o do direito à propriedade e pugnando pela preferência daquele em relação a este. De certa forma, o objeto deste trabalho dá continuidade ao desenvolvimento daquelas pesquisas, já que, aqui, também se busca pela autonomia e prevalência da moradia sobre a propriedade que não cumpre sua função social.
} 
A respeito de teorias sobre a posse, as mais utilizadas ainda repousam sobre os escritos de Savigny e de Ihering, datadas do século XIX e, em que pesem suas distinções, concordam em alguns pontos sobre constituição dos elementos da posse, sendo eles o material e o moral ou intelectual.

Para Savigny, a posse é o poder que detém a pessoa de dispor fisicamente de uma coisa (corpus) com a intenção de tê-la para si (animus), que não considerava como posse o simples elemento corpus, que caracterizaria mera detenção. Já no entendimento de Ihering, o corpus já seria elemento necessário e suficiente para caracterização da posse. Conforme aponta Ihering, a posse "acompanha sempre a utilidade econômica da propriedade e o proprietário não tem que recear que o direito o abandone, enquanto usar da coisa de um modo conforme seu destino" (IHERING,1908, p. 242).

Em suma, Batista e Mastrodi (2016, p. 1530) explicam:

[..] em matéria possessória, enquanto Savigny se ocupa, predominantemente, com o íntimo da atitude anímica, conformando-se com a vontade tendente para a propriedade (teoria subjetiva), Ihering identifica a subordinação desse instituto a uma realidade objetiva, defendendo a proteção possessória como exteriorização da propriedade (teoria objetiva).

Apesar de o Código Civil Brasileiro não dar uma definição a posse, acabou por estabelecer o conceito de possuidor, aderindo à teoria de Ihering, reconstruída na concepção da função social, conforme consta do art. 1.196 do Código Civil.

Ainda durante a pesquisa inicial para o desenvolvimento deste trabalho, percebemos que a doutrina brasileira não possui qualquer definição concreta do que seria a segurança da posse. Tal definição só é encontrada nos textos internacionais, quais sejam, a Recomendação Geral n. 4 do Comitê das Nações Unidas para os Direitos Econômicos, Sociais e Culturais, a Agenda Habitat II e a meta 11 dos objetivos do Milênio que, não obstante, não se encontram formalmente integradas ao nosso ordenamento jurídico interno.

O instituto do direito real de habitação, específico e singularizado para situação excepcional, que não admite pelas regras de interpretação sua aplicação extensiva, pareceu-nos ser a única hipótese em que o morador possui segurança jurídica de posse contra o proprietário do imóvel, segurança numa extensão que atende os critérios dos documentos internacionais acima mencionados.

O direito à moradia e, em especial, o seu componente de segurança jurídica da posse, tem que garantir um grau de proteção contra ameaças de despejos forçados ou de remoção, devendo ser aplicado a todos os tipos de regimes de habitação, garantindo assim proteção efetiva a 
qualquer morador, de qualquer moradia, mesmo contra o proprietário do imóvel. Segurança jurídica da posse se depreende que o morador tenha assegurada a continuidade da ocupação ao longo do tempo, sem que haja ameaça da manutenção de seu direito à moradia.

A situação de ocupação irregular, em regra, deixa os moradores em condição de ameaça ao seu direito à moradia, já que são considerados, aos olhos do Direito Civil, não como titulares de um direito (à moradia), mas como violadores do direito do proprietário.

No entanto, por força de normas constitucionais, em especial o inciso XXIII do artigo 5ㅇ, que impõe o exercício da função social de qualquer propriedade, não faz sentido entender o morador, ocupante de um imóvel até então subutilizado ou sem qualquer utilização, exerça uma conduta ilícita. Ou que a falta de um título jurídico seja condição que impeça o exercício da moradia. No caso do direito real de habitação de cônjuge supérstite, por exemplo, a moradia é revestida de segurança da posse. Ainda que este morador esteja em situação irregular, pois não possui qualquer título que lhe confira o exercício desse direito, os proprietários do imóvel não possuem meios para promover qualquer ameaça à sua posse.

O Estado não deveria restringir o desfrute ou o gozo do direito à moradia, devendo facilitar a promoção e o desenvolvimento das melhores condições possíveis para seu exercício, independentemente de o assentado ter ou não título de posse em termos legais, conferindo todos os meios necessários a impedir que estes sejam expulsos à força de suas casas:

[...]Na América Latina isso significa que as legislações nacional e local devem prever instrumentos jurídicos e urbanísticos que reconheçam o direito das pessoas a permanecer no local onde residem com segurança e proteção contra despejos e desastres naturais, independentemente do tipo de posse exercido: ocupação de área pública, ocupação de área privada, ocupação de prédios abandonados, aluguel, sistema cooperativado, compra de lote em parcelamento irregular; casa de emergência, propriedade individual, propriedade coletiva, posse de áreas tradicionais, etc. (ALFONSIN e FERNANDES, 2004, p. 35-36).

Em 1996, o Brasil assinou a Agenda Habitat, documento confeccionado durante a Conferência das Nações Unidas para os Assentamentos Humanos - Habitat II, em Istambul. Essa agenda propõe que todos os Estados signatários devem tomar providências que favoreçam a efetivação do direito à moradia para todos, bem como permitir o acesso igualitário à moradia, a proteção contra a discriminação e meio que torne acessível financeiramente a aquisição de moradia a todos. No entanto, cabe fazer a ressalva que ainda não houve o procedimento próprio de ratificação desse documento internacional, para que possa ser exigido internamente do Estado brasileiro. 
Ademais, a Agenda Habitat afirma em seu parágrafo 75 que "o acesso à terra e à segurança legal da ocupação constituem o fundamento essencial da disponibilização de uma habitação condigna a todas as pessoas" (ANISTIA INTERNACIONAL, 2011, p.102). Sendo assim, o Brasil, como signatário de tal acordo, tem que promover a segurança legal da posse, bem como assegurar o acesso à moradia.

No tocante a essa questão, a Declaração de Istambul, em sua seção III, item 8, determina a toda comunidade internacional o compromisso dos Estados membros de realizarem completa e progressiva promoção do direito à moradia adequada. Assim, os resultados do seu Plano Global de Ação devem ser um compromisso de implementação a serem constantemente monitorados e avaliados por estes.

A Agenda Habitat, do Programa das Nações Unidas para Assentamentos Humanos, está diretamente relacionada com a Declaração do Milênio ${ }^{17}$ (NAÇÕES UNIDAS, 2000, p. 2), que determina metas a serem alcançadas pelos Estados membros, que têm um prazo máximo para executar as medidas necessárias para atingimento das metas em cada Estado. Dentre as metas do milênio, importa-nos, no presente caso, a meta 11, constante do objetivo 7 da Declaração do Milênio e inserida no Diálogo 1 da Conferência:

Meta 11 - Até 2020, atingir uma significativa melhora na qualidade de vida de 100 milhões de habitantes de moradias inadequadas:

[...]l-32 Proporção de pessoas com posse segura da moradia (propriedade escriturada ou aluguel). (PNUD, 2004. p. 20)

Entretanto, não existem dados organizados sobre o $1-32$, que trata da posse segura da moradia. Seria necessário grande esforço para estabelecer essas informações de maneira consistente e confiável. Deverá haver esforço, também, para que essa meta seja efetivamente cumprida. Não faz sentido que o Estado queira justificar o descumprimento de um Pacto, firmado por ele e devidamente ratificado e internalizado no ordenamento jurídico, sob a alegação de falta de recursos. Ainda que se declare incapaz de cumprir as obrigações básicas acordadas, terá que comprovar que está fazendo todo o esforço possível para realizar suas obrigações essenciais. No caso específico do direito à moradia, cabe ao Estado demonstrar que os recursos, embora

\footnotetext{
${ }^{17}$ A Declaração do Milênio das Nações Unidas é um documento que reflete "as preocupações dos dirigentes mundiais de 147 Chefes de Estado e de Governo e de 191 países. " (CIMEIRA DO MILÊNIO, 2000, p. 2). A Declaração trouxe medida e metas globais para atender a novos anseios e exigências ao novo século (PNUD, 2004).
} 
insuficientes no presente, serão estruturados de forma a garantir a concretização dos direitos previstos no documento internacional. ${ }^{18}$

\section{O INSTITUTO DO DIREITO REAL DE HABITAÇÃO}

Comumente, o direito real de habitação é tratado como a garantia ao cônjuge sobrevivente, que, mesmo não recebendo legado ou não tendo direito à partilha, pode permanecer gratuitamente no imóvel que the serve de moradia.

O instituto, ora estudado, tem forma gratuita e só acaba com a morte do habitador, garantindo a moradia do cônjuge sobrevivente no único imóvel destinado à residência da família, conforme prescreve o artigo 1831 do Código Civil.

Ademais, ressalta-se que o reconhecimento também se dá ao companheiro, conforme consolidado pelo Conselho da Justiça Federal, da I Jornada de Direito Civil, no Enunciado 117, afirma que: "O direito real de habitação deve ser estendido ao companheiro, seja por não ter sido revogada a previsão da Lei n. 9.278/96, seja em razão da interpretação analógica do art. 1831, informado pelo art. 6을 caput, da CR/88" (CONSELHO DA JUSTIÇA FEDERAL, 2002, p. 17).

O entendimento firmado por tal enunciado foi que o direito real habitação deve ser estendido aos companheiros sobreviventes, até então não era reconhecido, uma vez que a previsão legal acerca do direito real de habitação era expressa exclusivamente em relação ao cônjuge supérstite. Admitindo-se, assim, o direito real de habitação para fins unicamente possessórios, bastando, para tanto, o reconhecimento judicial da união estável entre o proprietário do imóvel, falecido, e o morador.

Segundo Clóvis Bevilácqua, esse instituto deve estar restrito ao direito de morar, ou seja, deve-se tão somente ocupá-lo, sendo considerado, por sua natureza, direito personalíssimo. Conforme descreve:

Habitação é o direito real de habitar, gratuitamente, casa alheia. O titular deste direito não pode emprestar, nem alugar a casa, mas, apenas ocupá-la com a sua família... Como o usuário, o habitador não é obrigado a reparações, e o seu direito, não havendo limitação no título, dura com a sua vida. Limitando-se ao direito de morar, não pode a habitação abranger o uso da casa para estabelecimento industrial ou comercial, salvo se nela reside o habitador (BEVILÁCQUA, 2003, p. 321).

\footnotetext{
18 Sobre a teoria da reserva do possível e seus limites em relação ao direito à moradia, cf. Mastrodi e Rosmaninho (2013).
} 
A segurança proporcionada no caso do direito real de habitação é suficiente para dar ao morador condições para reconhecer sua moradia como digna ou adequada; caso alguém venha a ameaçar tal direito, poderá usar de meio judicial para tutelar sua posse. Esse entendimento encontra-se cristalizada até mesmo em manuais de Direito Civil, como o de Gonçalves que, ao tratar do direito real de habitação, assevera que:

O instituto em apreço assegura ao seu titular o direito de morar e residir na casa alheia. Tem, portanto, destinação especifica: servir de moradia ao beneficiário e sua família. Não podem alugá-la ou emprestá-la. Acentua-se, destarte, a inacessibilidade assim do direito quanto do seu exercício. (GONÇALVES, 2009, p. 480).

Deste modo, o imóvel objeto do direito real de habitação somente poderá servir à moradia de seu habitante, ficando este obrigado a pagar os tributos e benfeitorias necessárias para a conservação do imóvel. Este direito de habitar, além de inalienável, é também impenhorável e só se extingue com a morte de seu titular.

Como observa Pontes de Miranda, o direito real de habitação:

[...] é servidão pessoal limitada, que recai sobre todo ou parte de imóvel. O proprietário pode, ao constituí-lo, reservar-se o direito de também habitar no prédio, ou em parte dele. Só há gravame de todo o prédio, no primeiro caso; no segundo, só parte real é gravada. O proprietário tem a faculdade de reservar para outra pessoa, ou a futuro proprietário, o direito de também habitar, ou estabelecer que, à sua morte, ou a outro acontecimento, o direito de habitação passe a ser só de parte (PONTES DE MIRANDA, 1971, p. 443).

Há, portanto, um reconhecimento específico para este caso, já que no Direito Civil se define que o direito real de habitação como um direito subjetivo totalmente exigível pelo titular do direito à moradia contra o titular do direito à propriedade do imóvel. Ou seja, o Direito confere segurança de posse do morador contra o proprietário do imóvel em que reside.

Deve-se apontar, aqui, a jurisprudência ${ }^{19}$ acerca da temática, como a afirmada pelo Tribunal de Justiça do Estado de São Paulo ${ }^{20}$ pela qual é garantido ao possuidor (cônjuge

\footnotetext{
${ }^{19}$ Foi realizado pesquisa na data de 8 de junho de 2016 no portal do próprio tribunal sobre julgados com as palavras-chave: "direito real de habitação". Foram encontrados 479 acórdãos julgados nos últimos quatro anos. Destes, a grande maioria reconhece e impõe o cumprimento deste instituto.

${ }^{20}$ Conforme descreve a ementa: "AGRAVO DE INSTRUMENTO. INVENTÁRIO. DIREITO REAL DE HABITAÇÃO. É assegurado à companheira sobrevivente o direito real de habitação previsto no artigo art. 1.831 do CC/02. Interpretação analógica que busca preservar o princípio geral da vedação ao retrocesso. Aplicação do Enunciado 117 do CJF. Ademais, a propriedade de outros imóveis pela agravada não afasta, por si só, o seu direito real de habitação no imóvel em que ela e o de cujus fixaram a residência da família. Precedentes jurisprudenciais. Decisão mantida. RECURSO NÃO PROVIDO". (TJ-SP Al: no 21966881320148260000 Rel. Rosangela Telles, 2015.) Nesse mesmo sentido: "Apelação. Ação de Cobrança de Alugueis de Condômino.
}

Revista de Direito da Cidade, vol. 09, no 1. ISSN 2317-7721 pp. 27-49 42 
supérstite) o direito de permanecer no imóvel em que mora, não podendo sofrer qualquer tipo de ameaça ou lesão à sua posse, tendo o morador, portanto, de fato e de direito, a segurança jurídica da posse em termos análogos, se não idênticos, aos previstos no conceito de moradia digna dado pela Recomendação n. 4 do Comitê das Nações Unidas para os Direitos Econômicos, Sociais e Culturais.

Nesta mesma direção estão, também, os julgados do Tribunal de Justiça do Estado do Rio de Janeiro. ${ }^{21}$ Em que pese o fato de, neste tribunal, quase não há julgados a este respeito. Nos vários acórdãos, ${ }^{22}$ todos anteriores à vigência do Código Civil de 2002, o sentido encontrado foi o de não preservar o direito real de habitação. $O$ entendimento de que o instituto do direito real à habitação deve ser preservado nesse Tribunal é menos recorrente quando comparado, como por exemplo, ao Tribunal de Justiça do Estado de São Paulo.

Réu e genitora que ocupam com exclusividade imóvel pertencente também ao Autor. Direito real de habitação reconhecido à genitora das partes, cônjuge sobrevivente, que habita o imóvel que já era utilizado como residência do casal. Inteligência do artigo 1.831 do CC. Titular do direito real de habitação que consentiu o uso do imóvel a um dos filhos herdeiros. Impossibilidade de cobrança de alugueis, enquanto pendente o direito real de habitação. Precedente jurisprudencial. Sentença mantida. Recurso não provido". (TJ-SP APL: no: 0013438-19.2012.8.26.0408. Rel. João Pazine Neto, 2014.)

${ }^{21}$ Ementa: "Apelação cível. Ação possessória. União estável. Direito real de habitação. Apelante que se insurge contra a reintegração de posse determinada pelo juízo a quo. Esbulho. Inocorrência. Companheira que tem direito real de habitação sobre o imóvel em que residia com o companheiro falecido. Ônus real que passa a gravar a propriedade dos apelantes. Inteligência do art. 70, parágrafo único, da Lei 9278/96. Precedentes do STJ. Legitimidade da posse exercida pela apelante. Ausência de esbulho possessório. Possibilidade de o cônjuge supérstite defender sua posse com base em direito real de habitação. Precedentes do STJ. Recurso a que se dá provimento, na forma do art. 557 § 10-A CPC. (TJ-RJ APL: 01769875420128190004 RJ, Rel. Des. Cristina Tereza Gaulia, 2014.)

Ementa: "Apelação cível. Ação de imissão na posse. Direito real de habitação de cônjuge supérstite em conflito com direito de propriedade de herdeira, filha do falecido. Sentença de procedência parcial determinando coabitação às partes. Impossibilidade. Necessidade de ponderação dos interesses em conflito. Prevalência do direito real de habitação, de modo a assegurar o direito de moradia. Precedentes do 0stj e deste tribunal de justiça do rio de janeiro. Recurso a que se dá provimento, na forma do artigo $557 \S 1$ 1-a do CPC, para determinar que a apelada deixe o imóvel, mantida a posse com a apelante". (TJ-RJ - APL: 01275398720138190001 RJ, Relator: Des. Lucia Helena do Passo, 2015.)

${ }^{22}$ Em 8 de junho de 2016, pesquisamos no portal do Tribunal com as palavras-chave "direito real de habitação", foram encontrados aproximadamente 70 resultados sobre a temática. Nos últimos 4 anos, há 69 acórdãos julgados. Destes, 5 impõem cumprimento do instituto. Apesar de alguns julgados terem embasamento no artigo 1.611, §2º, do Código de 1916, o entendimento é basicamente o mesmo, no sentido de proteger e exigir o cumprimento do instituto. 
No âmbito do Superior Tribunal de Justiça, ${ }^{23}$ o entendimento tem-se consolidado no mesmo sentido, sendo possível identificar um consenso jurisprudencial ${ }^{24}$ no que diz respeito ao direito real de habitação, que assegura a moradia vitalícia ao cônjuge supérstite, nos precisos termos da segurança jurídica da posse.

Conforme afirmamos anteriormente, não há nenhum impedimento para se considerar o direito real de habitação, consolidado pela doutrina e pela jurisprudência como direito subjetivo do morador na hipótese de este ser cônjuge supérstite, como direito subjetivo de qualquer morador em situação ocupação mansa e pacífica de imóvel alheio. Ou seja, não há justificativa para se considerar tal direito apenas em caso de cônjuge supérstite na área do direito de família.

As duas situações são, para além de análogas, simplesmente idênticas. Em ambos os casos, seja na hipótese de cônjuge supérstite, seja na hipótese de morador em situação "irregular" (isto é, de mera ocupação), o direito à moradia e a função social da posse se impõem de igual maneira, determinando-se a aplicação da segurança jurídica da posse em ambas as situações. Nesse sentido, a segurança da posse deve ser considerada universal, em qualquer disputa envolvendo moradia, e não apenas nas questões entre cônjuge supérstite e herdeiros do imóvel em que ele resida.

Sim, é verdade que o direito real de habitação é bem compreendido no âmbito do direito privado, já que o Código Civil expressamente o garante, na hipótese do cônjuge supérstite, nos termos de seu artigo 1831. Não obstante, o direito à moradia de imóveis ocupados tem a seu favor, para que se lhe estenda igual segurança jurídica da posse, o inciso XXIII do artigo 5o, assim como o artigo 6ำ ambos da Constituição Federal, e o artigo 39 do Estatuto da Cidade.

Talvez a situação do cônjuge sobrevivente seja mais fácil de ser resolvida por causa da previsão expressa de um artigo de lei, facilmente identificado pela subsunção do fato ao texto literal do Código Civil. Porém, eventual dificuldade de identificação dos vários textos normativos que protegem o morador que ocupa imóvel, imóvel este que não cumpre sua função social, não deve impedir que haja segurança jurídica da posse tal qual no caso do direito real de habitação.

23. Ementa: "DIREITO CIVIL. DIREITO DE FAMÍLIA E SUCESSÃO. DIREITO REAL DE HABITAÇÃO DO CÔNJUGE SOBREVIVENTE. RECONHECIMENTO MESMO EM FACE DE FILHOS EXCLUSIVOS DO DE CUJOS. 1. - O direito real de habitação sobre o imóvel que servia de residência do casal deve ser conferido ao cônjuge/companheiro sobrevivente não apenas quando houver descendentes comuns, mas também quando concorrerem filhos exclusivos do de cujos. 2. - Recurso Especial improvido". (STJ Resp no 1134387 SP 2009/0150803-3. Rel: Ministra Nancy Andrighi, 2013.)

${ }^{24}$ Também foi realizada, em 8 de junho de 2016, pesquisa no site do próprio Tribunal a respeito de julgados, também com as palavras-chave "direito real de habitação". Foram encontrados 50 Acórdãos, 5917 Decisões Monocráticas e 10 informativos de jurisprudência. Nos últimos 4 anos, há 19 acórdãos. Destes, todos impõem o cumprimento do instituto do direito real de habitação em favor de cônjuge supérstite. 
Como se pode perceber, a segurança da posse é indispensável para que o direito à moradia adequada possa ser preservado em todas as camadas da sociedade, independentemente da condição econômica do morador.

Nesse sentido, a União deve garantir e promover o acesso ao direito à moradia adequada, além do mais isso irá ajudar na concretização do direito à cidade, conforme asseveram Mastrodi e Silveira Zaccara (2016). ${ }^{25}$

O Estado não deve permitir que as pessoas desprovidas de recursos financeiros sejam tratadas de forma desigual apenas por serem pobres, já que, em tese, é esta a função garantidora do Estado, que possui o dever de agir para coibir quaisquer formas de violações a direitos. Apesar da igualdade e a proteção dessa igualdade estarem claramente previstas na Constituição Federal, tais abusos são por demais recorrentes. Os pobres são removidos fácil e rapidamente de suas moradias, sem condições de buscar proteção a partir da segurança jurídica de sua posse. Situação bem diferente daquela garantida ao cônjuge sobrevivente, que pode exercer seu direito real de habitação sem qualquer constrangimento.

\section{CONSIDERAÇÕES FINAIS}

Destaca-se que o objetivo do estudo foi confirmado. Do ponto de vista da eficácia do direito humano à moradia digna ou à moradia adequada, há que se proteger a posse do imóvel para fins de moradia do mesmo modo que se protege a propriedade abstrata de qualquer bem. Aliás, há que se dar segurança jurídica da posse a qualquer moradia, exatamente como já ocorre com o próprio direito de moradia no âmbito do direito de família, ali denominado direito real de habitação, nos termos do art. 1831 do Código Civil.

Do mesmo modo que o direito de família cristalizou proteção jurídica à posse do cônjuge supérstite contra o direito de propriedade dos herdeiros do imóvel ocupado, a teoria do direito e o atual ordenamento jurídico conferem proteção jurídica a qualquer posse de imóvel para fins de moradia, desde que ociosos, contra o direito de seus proprietários. Se o cônjuge supérstite tem direito de morar de modo manso e pacífico e possua garantia jurídica de sua posse a partir de um artigo do Código Civil, não há impedimento algum para se considerar como igualmente lícito que

\footnotetext{
25 [...] o direito à moradia deve ser entendido como um forte elemento de concretização do direito à cidade, motivo pelo qual se justifica a necessidade de que políticas públicas sejam definidas de modo a garantir que haja uma certa vinculação em promover Habitações de Interesse Social em locais em que já exista cidade, e não em locais afastados, sem qualquer equipamento público (Mastrodi e Silveira Zaccara, 2016, p. 24).
} 
moradores de imóveis ocupados tenham igual segurança para seu direito a partir de um artigo de lei (em especial, o 39 do Estatuto da cidade) e outros dois da Constituição Federal (o 5o, inciso XVIII, e o 6o), tudo conforme interpretação de documentos internacionais de proteção ao direito à moradia adequada.

\section{REFERÊNCIAS BIBLIOGRÁFICAS}

ALFONSIN, Betânia; FERNANDES, Edésio (Coord). Direito à moradia e Segurança da Posse no Estatuto da Cidade. Diretrizes, Instrumentos e Processos de Gestão. Belo Horizonte: Ed. Forum, 2004.

ANISTIA INTERNACIONAL (Org.). HAKI ZETU - Direitos ESC na prática - O direito a uma habitação condigna. Holanda: Programa Especial para a África (SPA) da Amnistia Internacional Holanda, 2011. Disponível em: <https://www.amnesty.nl/sites/default/files/public/direito_a_uma_habitacao_condigna_light.pdf>. Acesso em: 02 abr. 2016.

BATISTA, Ana Carolina; MASTRODI, Josué. Existe um direito fundamental à posse? Estudo sobre a relativização do conceito de propriedade imobiliária urbana em face do direito de moradia. Revista de Direito da Cidade. vol. 07, n. 4. 2015. Número Especial. p. 1527-1554. Disponível em:< http://www.e-publicacoes.uerj.br/index.php/rdc/article/view/20907/15351> Acesso em: 11.abr.2016.

BEVILÁCQUA, Clóvis, Direito das coisas. 4 eds. vol. I. 2003. Disponível em: <http://www2.senado.leg.br/bdsf/bitstream/handle/id/496210/000667968_V1.pdf?sequence=1>. Acesso em 05 de abril.2016.

BRASIL. Constituição (1988). Constituição da República Federativa do Brasil. Brasília: Senado Federal, $1988 . \quad$ Disponível em: <http://www.planalto.gov.br/ccivil_03/Constituicao/Constituicao.htm>. Acesso em: 02.abr. 2016.

Lei no 10.257 , de 10 de julho de 2001. Regulamenta os artigos 182 e 183 da Constituição Federal, estabelece diretrizes gerais da política urbana e dá outras providências. Diário Oficial da União. Brasília, DF, 11 jul. $2001 . \quad$ Disponível em:< http://www.planalto.gov.br/ccivil_03/leis/leis_2001/l10257.htm>. Acesso em: 08.abr.2016.

Lei n. 10.406, 10 de janeiro de 2002. Código Civil. Diário Oficial da União, Rio de Janeiro,11 jan. 2002. Disponível em:< http://www.planalto.gov.br/ccivil_03/leis/2002//10406.htm >. Acesso em: $10 . f e v .2016$.

Lei no 11.124, de 16 de junho de 2005. Dispõe sobre o Sistema Nacional de Habitação de Interesse Social, cria o Fundo Nacional de Habitação de Interesse Social e institui o Conselho Gestor do FNHIS. Diário Oficial da União. Brasília, DF, 17 jun. 2005. Disponível em:< http://www.planalto.gov.br/ccivil_03/_ato2004-2006/2005/lei/l11124.htm>. Acesso em: 08.abr.2016.

Lei no 10.257/2001, Estatuto da Cidade. Disponível em http://www.planalto.gov.br/ccivil_03/leis/LEIS_2001/L10257.htm Acesso em: 04.abr. 2016. 
Secretaria de Direitos Humanos da Presidência da República. Por uma Cultura de Direitos Humanos: Direito à moradia adequada. Brasília: Coordenação Geral de Educação em SDH/PR, Direitos Humanos, Secretaria Nacional de Promoção e Defesa dos Direitos Humanos, 2013. Disponível em: <http://www.sdh.gov.br/assuntos/bibliotecavirtual/promocao-edefesa/publicacoes-2013/pdfs/direito-a-moradia-adequada>. Acesso: 02. abr. 2016.

Superior Tribunal de Justiça. Recurso Especial: Resp no 1134387 SP 2009/0150803-3, T3 Terceira Turma. RECORRENTE: MÔNICA PROTO DARIOLLI E OUTROS. RECORRIDO: REGINA DE FÁTIMA BICUDO PROTO E OUTROS. Relator: Ministra NANCY ANDRIGHI. Diário da Justiça Eletrônico (dje). Data de Publicação 29 de maio de 2013.

Tribunal de Justiça do Estado de Rio de Janeiro. Ementa: Apelação cível. TJ-RJ - APL: 01769875420128190004 RJ 0176987-54.2012.8.19.0004, QUINTA CAMARA CIVEL. Relator: DES. CRISTINA TEREZA GAULIA. Data de Julgamento: 05/12/2014. Data de Publicação: 16 de dezembro de 2014.

Tribunal de Justiça do Estado de São Paulo. Acórdão: Arguição de Inconstitucionalidade (AI): no 21966881320148260000. Suscitante: 2ª Câmara de Direito Privado do Tribunal de Justiça de São Paulo. Relator: Rosangela Telles, São Paulo, 03.abr. 2016.

Tribunal de Justiça do Estado de São Paulo. Acórdão: Apelação no: 001343819.2012.8.26.0408. Suscitante: 3ạ Câmara de Direito Privado do Tribunal de Justiça de São Paulo. Relator: João Pazine Neto, São Paulo, 14 de agosto de 2014.

Tribunal de Justiça do Estado de São Paulo. Acórdão no 2110607-27.2015.8.26.0000. voto n. ㅇ 20.795, órgão julgador: 12a Câmara de Direito Público do Tribunal de Justiça de São Paulo. Cícero Vicente da Silva. Fazenda Pública do Estado de São Paulo e do município de São José dos Campos e Selecta Comércio e Indústria S/A. Relator: Osvaldo de Oliveira. São Paulo, São Paulo, 08 de janeiro de $2015 . \quad$ Disponível em: $<$ https://esaj.tjsp.jus.br/cjsg/getArquivo.do?cdAcordao=8783484\&cdForo=0 >. Acesso em 08.set. 2016.

CONSELHO DA JUSTIÇA FEDERAL. I Jornada de Direito Civil, no Enunciado 117, 2002, p. 17. Disponível em: <http://daleth.cjf.jus.br/revista/enunciados/IJornada.pdf.> Acesso em: 08.abr. 2016.

COSTA, Dilvanir José. O sistema da posse no Direito Civil. Revista de Informação Legislativa, a. 35, n.139, 1998, p. 109-117. Disponível em: <http://www2.senado.leg.br/bdsf/item/id/391>. Acesso em 14.set.2016.

COSTA, Rafael de Oliveira. Segurança jurídica e (im)previsibilidade do Direito. Nomos. v. 34, n.1, 2014, p. 169-202. Disponível em: <http://www.periodicos.ufc.br/index.php/nomos/article/view/1193/1159>. Acesso em: 14.set.2016.

DESOCUPAÇÃO DA VILA SOMA SERÁ UMA DAS MAIORES DA JUSTIÇA DE SP. SUmaré, 10 maio 2015. Disponível em: <http://correio.rac.com.br/_conteudo/2015/05/capa/campinas_e_rmc/257392vila-soma-as-duas-faces-de-um-drama.html>. Acesso em: 13 set. 2016.

GONÇALVES, Carlos Roberto. Direito Civil Brasileiro. Direito das Coisas. v.5. 4ạ. ed. São Paulo: Saraiva, 2009. 
IHERING, Rudolf Von. O fundamento dos interditos possessórios. Trad. Aderbal de Carvalho. 2. ed. Rio de Janeiro, Francisco Alves, 1908.

MASTRODI, Josué; ISAAC, Gabriela Martins. A construção do direito à cidade entre o interesse público e o interesse dos agentes do mercado imobiliário: um estudo de caso a partir do plano local de gestão de Barão Geraldo, em Campinas. Revista de Direito da Cidade, v. 8, n. 2, 2016, p. 729-748. Disponível em: <http://www.epublicacoes.uerj.br/index.php/rdc/article/view/21772/16256>. Acesso em: 08.maio.2016.

MASTRODI, Josué; MARTINS, Ester Gouvêa. Direito à moradia: entre a efetivação autônoma e a sujeição ao direito de propriedade. Mimeo, 2016.

MASTRODI, Josué; ROSMANINHO, Mariane Dantas. O Direito Fundamental à Moradia e a Existência Efetiva da Reserva do Possível. Revista Eletrônica Direitos Fundamentais \& Democracia, v. 14, n.14.1, jul/dez. 2013, p. 113-134. Disponível em: $<$ http://revistaeletronicardfd.unibrasil.com.br/index.php/rdfd/article/view/317/333>. Acesso em: 08. abr. 2016.

MASTRODI, Josué; ROSSI, Renan Alarcon. Direito fundamental social à moradia: aspectos de efetivação e sua autonomia em relação ao direito de propriedade. Revista Direitos Fundamentais \& Democracia, Curitiba v. 17, n. 17, jan/jun de 2015, p. 168 -187. Disponível em: <http://revistaeletronicardfd.unibrasil.com.br/index.php/rdfd/article/view/549/420>. Acesso em: 11.abr.2016.

MASTRODI, Josué; SILVEIRA ZACCARA, Suzana Maria Loureiro. Sobre a promoção do direito à moradia: um estudo à luz da política urbana do município de Campinas. Revista de Direito da Cidade, v. 8, n. 1, 2016. p. 1-28. Disponível em: < http://www.epublicacoes.uerj.br/index.php/rdc/article/view/18518/15665>. Acesso em: 02.maio. 2016

NAÇÕES UNIDAS. Declaração do Milénio, Cimeira do Milénio, Nova York, 2000. Disponível em: <http://www.pnud.org.br/Docs/declaracao_do_milenio.pdf >. Acesso em: 02.abr. 2016

Declaração Universal dos Direitos Humanos. Brasília: Ministério das Relações Exteriores, Ministério da Justiça, $1948 . \quad$ Disponível em: $<$ http://portal.mj.gov.br/sedh/ct/legis_intern/ddh_bib_inter_universal.htm>. Acesso em: 02.abr. 2016

Pacto Internacional sobre Direitos Econômicos, Sociais e Culturais. Adotado pela Assembleia das Nações Unidas em 16 de dezembro de 1966 e em vigor em 3 de janeiro de 1976, ratificado pelo Brasil em 24 de janeiro de 1992. Brasília: Ministério das Relações Exteriores, Ministério da Justiça, 1992. Disponível em: < http://www.direitoshumanos.usp.br/index.php/Sistema-Global.Declara\%C3\%A7\%C3\%B5es-e-Tratados-Internacionais-de-Prote\%C3\%A7\%C3\%A30/pacto-

internacional-dos-direitos-economicos-sociais-e-culturais-1966.html> .Acesso em: 05 de abr. 2016.

Recomendação Geral no 4 do Comitê de Direitos Econômicos, Sociais e Culturais acerca do Artigo 11 do Pacto Internacional de Direitos Econômicos, Sociais e Culturais. Genebra, 1991. Disponível em: <http://www.dhnet.org.br/direitos/sos/moradia/trabalhohabitacaopronto.html>. Acesso em: 06. abr. 2016. 
Comentário Geral no 4 do Comitê de Direitos Econômicos, Sociais e Culturais, de 12 de dezembro de 1991[A]. Disponível em: <http://www.gddc.pt/direitos-humanos/Ficha_16.pdf>. Acesso em: 08 abr. 2016.

UN-Habitat. The right to adequate housing. Geneva: Office of the United Nations High Commissioner for Human Rights; New York: UN-Habitat, 2009. Disponível em: $<$ http://www.ohchr.org/Documents/Publications/FS21_rev_1_Housing_en.pdf>. Acesso em: 08 abr. 2016.

PONTES DE MIRANDA, Francisco Cavalcanti, Tratado de Direito Privado. 3a Ed. Tomo VII. Rio de Janeiro: Editora Bolsoi, 1971.

ROUSSEAU, Jean-Jacques. Discurso sobre a origem e os fundamentos da desigualdade entre os homens. Trad. Maria Ermantina Galvão. São Paulo: Martins Fontes, 1999.

SAULE JÚNIOR, Nelson; CARDOSO, Patrícia de Menezes. O Direito à Moradia no Brasil. São Paulo: Instituto Pólis, 2005. p. 33 Disponível em: http://www.polis.org.br/uploads/911/911.pdf >. Acesso em 08 abr. 2016.

PNUD. Sustentabilidade ambiental: objetivo 7: garantir a sustentabilidade ambiental. Belo Horizonte: PUC Minas/IDHS, 2004. Disponível em: <http://www.ambiente.sp.gov.br/wpcontent/uploads/cea/objmilenio_sustamb.pdf >. Acesso em 08.abr. 2016.

Trabalho enviado em 09 de junho de 2016.

Aceito em 19 de setembro de 2016. 